\title{
The Step Forward: Options for the Displacement of Power Generation from Oil and Gas in Malaysia Using a System Dynamics Approach
}

\author{
Hsieh Y. Lee and Eng H. Yap, Senior Member, IACSIT
}

\begin{abstract}
Malaysia's power generation from oil and gas grows at an exponential rate, and is forecasted to be even more prominent in years to come. With rising global concerns over $\mathrm{CO}_{2}$ emissions and depleting resources, it has become vital for the country's power generating sector to be sustainable. This paper investigates the gradual displacement of Malaysia's reliance upon oil and gas to generate power using a system dynamics approach by simulating production over a 40 year period from 1985 to 2025 . With Malaysia aspiring to achieve its $\mathrm{CO}_{2}$ emissions reduction by $40 \%$ by 2020 from 2005 levels, this can be leapfrogged by considering alternative energy scenarios alongside the country's power generation from oil and gas.
\end{abstract}

Index Terms-Malaysia, oil and gas, system dynamics, displacement.

\section{INTRODUCTION}

Malaysia boasts a robust oil and gas market contributed by an abundance of crude oil and natural gas reserves available. From the 1970s, the industry has grown exponentially, along an increasing production and consumption of its oil and gas primarily for the purpose of power generation. This has prompted the focus required to ensure that the country's energy production and consumption remains sustainable.

There have been previous studies into the oil and gas industries using system dynamics method but none were conducted for Malaysia especially in this context. Furthermore, studies on oil and gas were usually focused on predicting the trends of consumption and production, or study of alternative renewable energy sources with regards to depleting oil and gas reserves. There have been few studies focusing on the displacement of the oil and gas industry in relation to the quantity of oil and gas produced and consumed but none was conducted using a system dynamics approach especially for an emerging economy like Malaysia.

This paper's aim is to investigate the trend of power generation from oil and gas, alongside addressing the level of $\mathrm{CO}_{2}$ emissions from these activities in Malaysia and to investigate possible options for their gradual displacement, in line with national and international aspirations. The trend of oil and gas production and consumption can be simulated using past data and forecasts, along with analysis of variables

Manuscript received October 10, 2014; revised November 29, 2014. The work carried out in this paper was a partial requirement for MM4MPR Individual Project for the MEng (Hon) in Mechanical Engineering.

Hsieh Yie Lee is with the University of Nottingham, Malaysia Campus, Semenyih, 43500, Malaysia (e-mail: janlee110@gmail.com).

Eng Hwa Yap is with the UCL School of Energy and Resources, University College London, Adelaide, 5000, Australia (e-mail: e.yap@ucl.ac.uk). affecting the power generation using oil and gas. The variables are model inputs enabling the analysis of how different variable inputs and scenarios will affect the level of production, consumption and their corresponding emissions.

Furthermore, with rising concerns over greenhouse gas (GHG) emissions, along with perceived contribution to global warming, the sustainability of Malaysia's power generation as a developing nation is paramount; and this paper aims to analyse how the level of $\mathrm{CO}_{2}$ emissions can be reduced by considering different options for its gradual displacement paving towards a sustainable future power generation for the country.

\section{POWER Generation USING OIL AND GAS IN MALAysia}

\section{A. Background}

Since 1985, Malaysia's oil and gas sector has grown in leaps and bounds. During the same period, oil production and consumption has increased by $50 \%$ and $200 \%$ respectively whilst gas production and consumption has increased by $400 \%$ [1]. As of 2012, Malaysia has proven oil reserves of 4 billion barrels (bbl), with a reserve-to-production ratio of 17.08 years, whilst proven gas reserves stand at 83 trillion cubic feet (tcf) with a reserve-to-production ratio of 34.14 years [1], [2].

Crude oil, petroleum products and natural gas remains the primary commercial energy supply in Malaysia, contributing to the power generation fuel mix in excess of $80 \%$, with coal and hydro supplementing the rests with $11 \%$ and $3 \%$ respectively in year 2000 [1]. In 2006, Malaysia's power generation fuel mix consists of $4 \%$ oil, $60 \%$ gas, $8 \%$ coal and $29 \%$ hydro/renewable energy (RE) sources [3]. Over the period of six years, the usage of oil has reduced significantly, taken over by natural gas for power generation. However, the usage of oil has increased for the transportation sector in Malaysia.

\section{B. Policies}

The National Energy Policy 1979 was adopted to ensure sufficient energy supply from both non-RE and RE sources, whilst effectively utilising resources with minimal negative environmental impacts [4]. The National Depletion Policy of 1980 came online to prevent over-exploitation of the country's oil and gas resources [4]. Similarly, the Four-Fuel Diversification Policy 1981 strategised the usage of oil, gas, coal and hydro and in 2001, the Five-Fuel Diversification Policy recognised RE as a main energy source [4]. Small Renewable Energy Program (SREP) was developed to boost RE sources usage in the country. These policies caused a drop 
in the usage of oil in the energy mix, from $88 \%$ in 1980 to $4.2 \%$ in 2000 [5]. However, the targeted $350 \mathrm{MW}$ power generated from RE in the Ninth Malaysia Plan (9MP) was not achieved, with less than 14MW generated from SREP [6].

The National Green Technology Policy followed in 2009, which takes into account the need for more efficient and environmentally friendly technologies [7], [8]. The policy also aimed to push Malaysia into a low carbon emission country with the usage of RE-based technologies such as biomass, biofuel, and wind. The New Energy Policy 2010, Renewable Energy Act 2011 and National Biomass Strategy 2020 were strategies aimed at increasing the use of RE sources in energy generation in order to mitigate their environmental impacts, and to compensate for non-RE sources such as oil and gas [1], [4].

\section{Current Emissions Status}

From current global GHG database, $81 \%$ is caused by fossil fuels, which releases 26,000 million metric tons equivalent (mmtoe) of $\mathrm{CO}_{2}$ [9]. It was also reported that as much as 18,000 mmtoe $\mathrm{CO}_{2}(60 \%)$ comes from consumption and production of oil and gas. Furthermore, 3,200 mmtoe $\mathrm{CO}_{2}(11 \%)$ comes from the industry in the form of losses, local heating and power generation. There are also other emissions such as $\mathrm{NO}_{\mathrm{x}}$ products and methane, but since $\mathrm{CO}_{2}$ contributes to more than $70 \%$ of GHG emissions, this paper will focus on $\mathrm{CO}_{2}$. For 2012, in Malaysia, the oil and gas consumption alone generated 79.247 mmtoe and 60.413 mmtoe of $\mathrm{CO}_{2}$ respectively, amounting to nearly $140 \mathrm{mmtoe}$ $\mathrm{CO}_{2}$ emitted from the consumption [10]. From the $15^{\text {th }}$ Conference of the Parties (COP15) meeting in Copenhagen, the Prime Minister of Malaysia, Najib Razak has committed Malaysia to reducing its $\mathrm{CO}_{2}$ emission intensity by $40 \%$ by 2020 from 2005 levels [11].

\section{Current Oil and Gas Trends and Future Predictions}

From the introduction of RE sources, along with an increased usage of natural gas in power generation, the production of oil is seen to be generally decreasing. This is in line with the fall of utilisable oil resources. However, oil consumption rate is forecasted to rise at a rate of 5 to $8 \%$ annually, and Malaysia is predicted to be a net oil importer in the future. For gas production and consumption, it is seen that the general trend is increasing at the rate of 3 to $5 \%$ annually. With consumption trend based on 1998-2010 oil and gas consumption, it is forecasted that the oil reserves and gas reserves are expected to last until 2035 and 2050 respectively [1], [2].

Currently, non-hydro RE sources such as biogas, biofuels, and waste energy sources only amounted to approximately $1 \%$ of the country's total energy supply and this is expected to increase to $9 \%$ by 2020 and $12 \%$ by 2030 [12]. At present, Malaysia has potential of up to $29,000 \mathrm{MW}$ of hydropower; however, only 5\% (2,091 MW) was utilised in 2008 [4]. The aim is to increase the generation of energy up to $35 \%$ (20GW) by 2030 . This would reduce the country's dependence upon natural gas from $60 \%$ in 2008 to $30 \%$ in 2030 [4].

The Economic Transformation Programme launched in 2010 include plans to build a twin-unit $1 \mathrm{GW}$ nuclear power plant (NPP), with commission of the two towers expected around 2020 [13]. This programme aimed to use nuclear power as the mainstay in energy generation for the country thus eliminating its dependence upon oil and gas.

\section{SYSTEM DYNAMICS}

System dynamics (SD) is a tool used to understand the dynamics of a complex system over time. The complex system modelled is capable of being examined and tested under different policies or scenarios to determine how the system is affected. Analysis of results allows more efficient or effective policies to be drafted. In this case, SD is useful as it allows the complex oil and gas industry system in Malaysia to be simulated as realistic as possible.

In SD modelling, the first step is to articulate the problem. The problem for the system examined is first identified. For Malaysia's oil and gas industry, the data was collected through extensive research on previous oil and gas production trend and data along with accumulating information on future forecast trends. This is mainly obtained by referring to official government reports, conference papers and international oil and gas statistics reports, such as the World Oil and Gas Review 2011. In this paper, the focus will be mainly on $\mathrm{CO}_{2}$ emissions and future oil and gas trends.

After the problem is determined, the variables affecting the problem are identified, and a hypothesis is formed. This is achieved by formulating a causal loop diagram (CLD) to show how the variables are related to one another. After identifying the relationships between variables, the model for the system is then constructed. The next step is formulation where the variables concerned are linked with mathematical equations, with their parameters such as initial values, units and growth rates obtained and determined through testing of the model. Numerous tests are performed on the model in which a feedback loop of testing and changing of parameters is carried out until finally the most suitable set of variable parameters are obtained and the model is able to properly simulate the system. The model is then validated with real data obtained.

After validation 1 , the model can also be further tested upon by examining how the implementation of different policies would affect the outcome. The effects are analysed and the results obtained are used to improve the system or to further improve the policies implemented. In this paper, the SD modelling and testing of scenarios using simulation are achieved using VENSIM [14], [15].

\section{Modelling MethodS AND VALIDATION}

\section{A. Backbone of the Model}

The dynamics of the oil and gas industry in Malaysia is examined by first determining the variables affecting $\mathrm{CO}_{2}$ emission from the industry. From the analysis of data, the CLD of the industry is shown in Fig. 1.

In this project, the emission of $\mathrm{CO}_{2}$ from Malaysia's oil and gas industry is contributed by two main variables: emissions from oil and gas consumption, and emissions from production. The oil and gas consumption and production in turn also affect the reserves available. The population's rate of growth directly affects the consumption rate, whilst the implementation of policies would affect production and emission, depending on the policies enacted. 


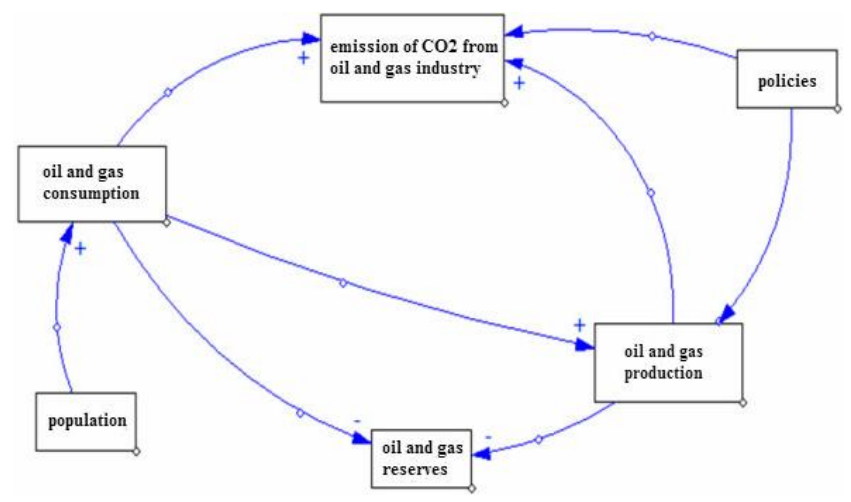

Fig. 1. Causal-loop diagram.

From the causal loop diagram, the backbone of the VENSIM model for Malaysia's oil and gas industry is constructed as shown in Fig. 2.

\section{B. Model Validation}

The above system was simulated from year 1985 to 2025 using VENSIM. The simulation results obtained were then compared with existing data for past oil and gas consumption and production. The comparisons are shown from Fig. 3 to Fig. 6.

From the results, it was shown that the VENSIM model has simulated the data in similarity to the real data for oil and gas production and consumption for similar period. The percentage of error between each data point is approximately 3 to $5 \%$. Therefore, the model is considered validated and sufficient to simulate the real-world dynamics of Malaysia's oil and gas production and consumption.

The backbone of the model shown in Fig. 1 is therefore considered as the basic model for the system, and will be termed as the Base Case Scenario (BASE).

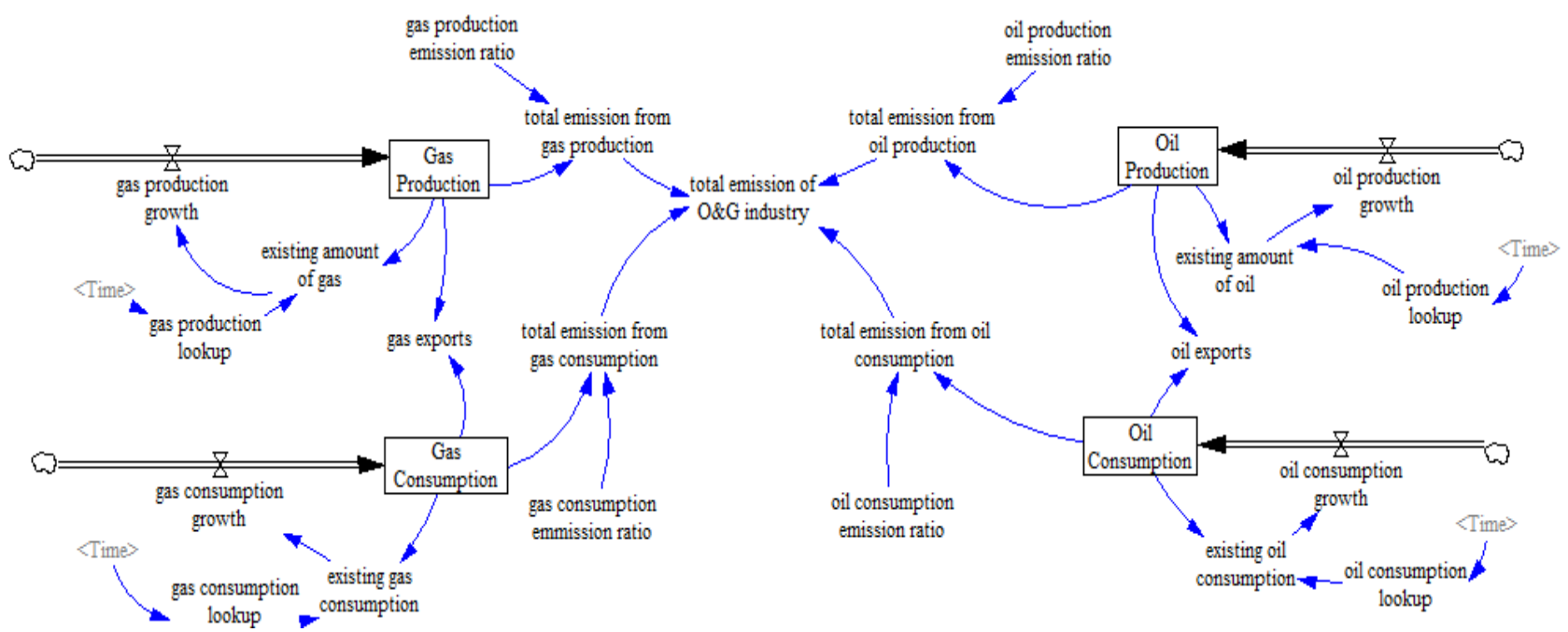

Fig. 2. Backbone of the system.

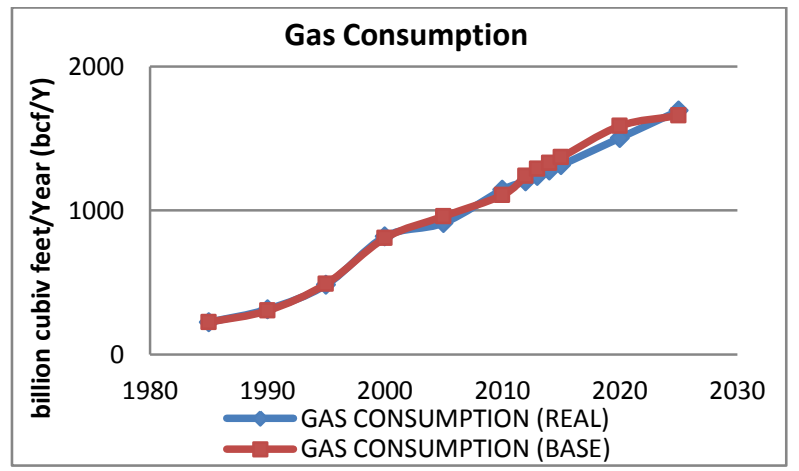

Fig. 3. Gas consumption comparison between real data and simulation data.

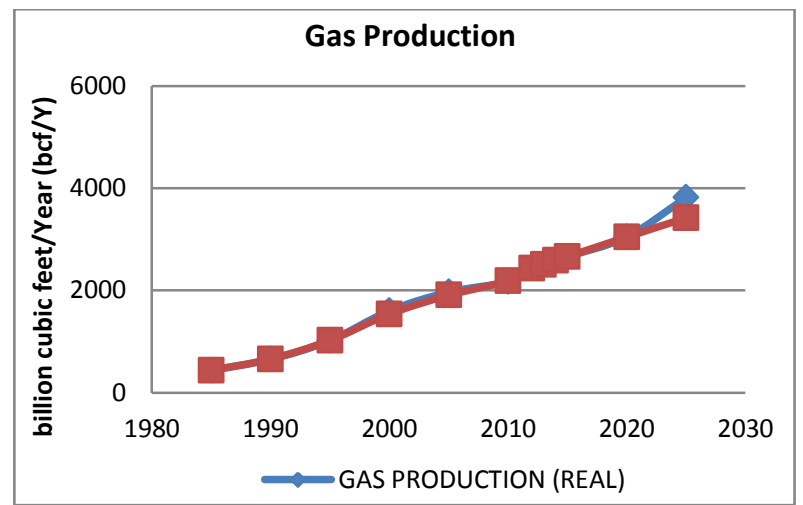

Fig. 4. Gas production comparison between real data and simulation data.

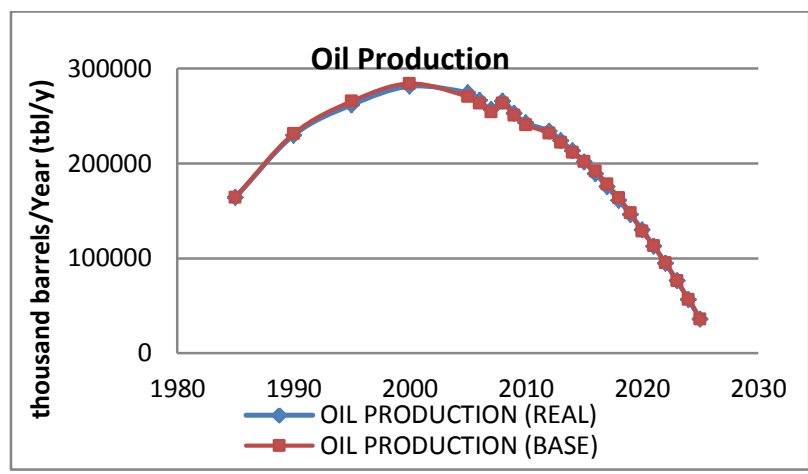

Fig. 5. Oil production comparison between real data and simulation data.

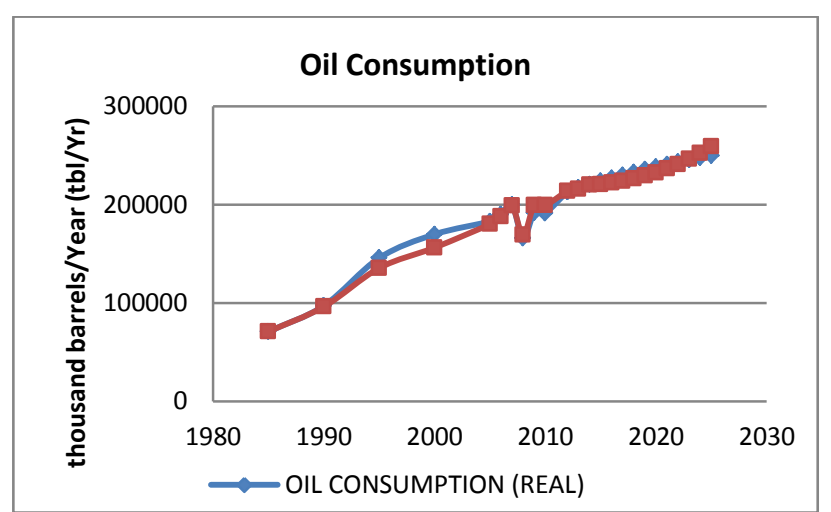

Fig. 6. Oil consumption comparison between real data and simulation data. 


\section{SCENARIOS FOR THE DisPlaCEMENT OF POWER GENERATION USING OIL AND GAS}

For the purpose of this study, there are four scenarios to be tested on the model as shown in Table I.

TABLE I: DESCRIPTION OF SCENARIOS IMPLEMENTED FOR SIMULATION
\begin{tabular}{|ll|}
\hline Scenario & Description \\
\hline $\begin{array}{l}\text { Base Case Scenario } \\
\text { (BASE) }\end{array}$ & $\begin{array}{l}\text { The business-as-usual scenario for the } \\
\text { current oil and gas industry without added } \\
\text { policies. }\end{array}$ \\
\hline $\begin{array}{l}\text { Scenario 1: } \\
\text { Renewable Energy } \\
\text { (RE) }\end{array}$ & $\begin{array}{l}\text { Hydro energy and other small RE sources } \\
\text { contribute to the energy supply from 2008 } \\
\text { onwards. }\end{array}$ \\
\hline $\begin{array}{l}\text { Scenario 2: Nuclear } \\
\text { Energy Scenario } \\
\text { (NUKE) }\end{array}$ & $\begin{array}{l}\text { Twin-unit 1GW nuclear power plant (NPP) } \\
\text { is operational by 2018 and 2019. }\end{array}$ \\
\hline $\begin{array}{l}\text { Scenario 3: } \\
\text { Combined Scenario } \\
\text { (ALL) }\end{array}$ & $\begin{array}{l}\text { RE and NPP are effectively implemented in } \\
\text { Malaysia. }\end{array}$ \\
\hline
\end{tabular}

The Base Case Scenario (BASE) is used as a base comparison case presenting business-as-usual (BAU). Scenario 1 is the Renewable Energy (RE) case, Scenario 2 is Nuclear Energy (NUKE) case and Scenario 3 is a lead scenario combining all scenarios (ALL).

\section{A. Renewable Energy Scenario (RE)}

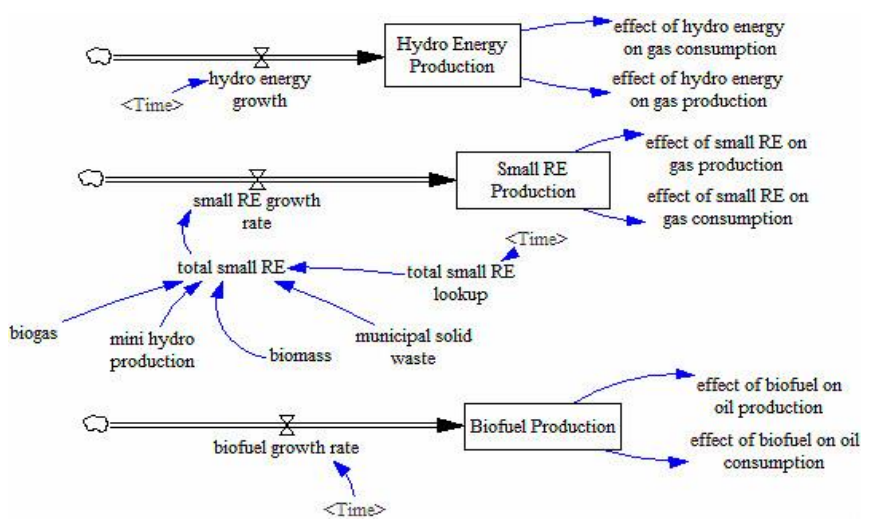

Fig. 7. Renewable energy subsystem model.

This scenario is concerned with the implementation of renewable energy sources as an alternative to oil and gas. Hydro energy contributes 2,091 MW in 2008, and is expected to increase to $20 \mathrm{GW}$ by 2025 . This increment is expected to cause a decrease of up to $30 \%$ natural gas production due to a projected shifting trend of preference over RE energies by the government. Small RE sources, such as biogas, biomass, mini hydro and municipal solid wastes are expected to increase by $30 \%$ in production from 2008 to 2025 . Biofuel production is expected to rise from 4,500 barrels/day to 100,000 barrels/day by 2025 . The subsystem model for the RE scenario is shown in Fig. 7.

\section{B. Nuclear Energy Scenario (NUKE)}

This scenario is concerned with the implementation of a twin-unit $1 \mathrm{GW}$ nuclear power plant (NPP), formed under the National Transformation Programme. In this scenario it is assumed that the first NPP is fully functional by 2018, and the second by 2019. Both NPPs will be capable of supplying a 2 GW combined production capacity for Malaysia, with a capacity factor of $85 \%$ assumed for each NPP. The subsystem for the nuclear energy scenario is shown in Fig. 8.

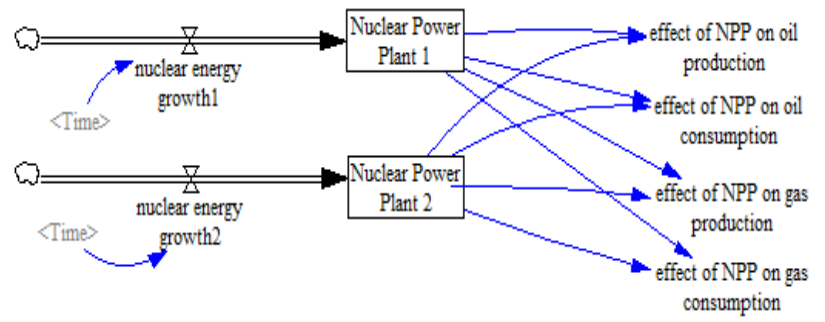

Fig. 8. Nuclear energy subsystem model.

\section{Combined Scenario (ALL)}

This scenario combined both the RE and NUKE scenarios into the BASE model. This scenario assumes that by year 2025, Malaysia will be mostly reliant upon renewable energy and nuclear to provide for its power generation fuel mix, and that natural gas and crude oil will not be the main sources of fuel for power generation but serving as backup sources. The final combined model for the system with all the effect of the scenarios linked is shown in Fig. 9.

\section{RESULTS AND DISCUSSIONS}

\section{A. Simulation Results}

The results from the gas production simulation are shown in Fig. 10. BASE scenario shows the highest amount of gas production, with a predicted volume of 3,420 billion cubic feet (bcf) to be produced in year 2025. For the RE scenario, gas production trend shows a predicted fall of $15 \%$ from the BASE scenario whilst for the NUKE scenario, gas production shows a trend of decrease by approximately $40 \%$. Combined scenario ALL shows the highest predicted decrease of $56 \%$ of gas production.

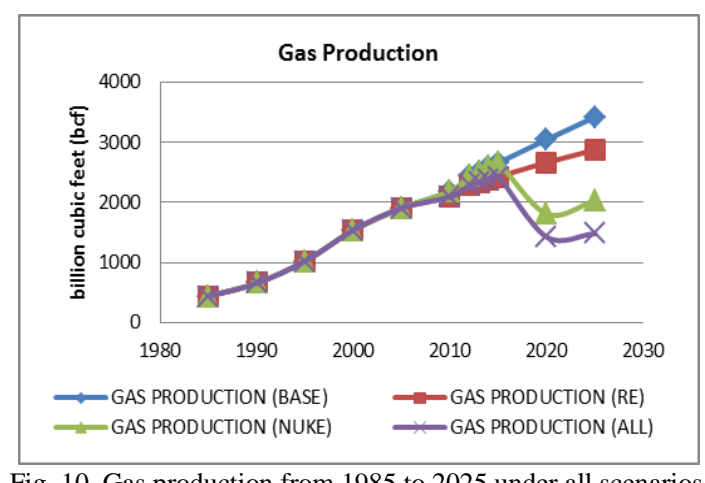

The results for gas consumption are shown in Fig. 11 where BASE scenario shows the highest amount of gas consumption of 1,619 bcf predicted in year 2025. For the RE scenario, the consumption decreases by $29.5 \%$ whilst for NUKE scenario, it decreases by $47 \%$. The combined scenario ALL is predicted to decrease by $80 \%$. For the RE scenario, the gas consumption decrease is exactly as predicted, which is approximately $30 \%$ with the increase in RE production.

The results for oil production is shown in Fig. 12. For the BASE scenario, oil production is predicted to decrease to 36,000 thousand barrels per year in year $2025,29.3 \%$ in the RE scenario and $18 \%$ for NUKE scenario. For the combined scenario ALL, the oil production amount is predicted to decrease by $47 \%$. 


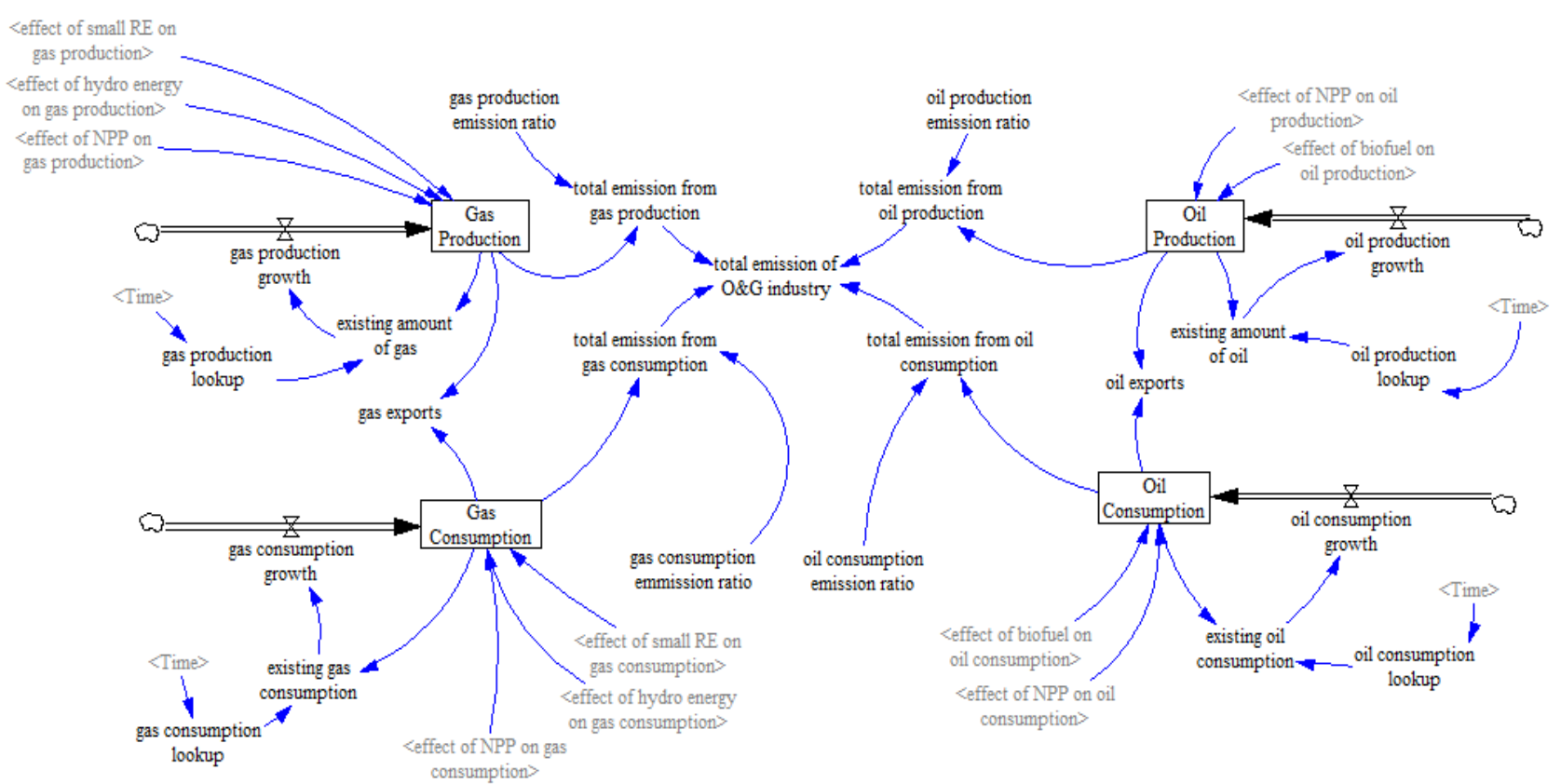

Fig. 9. Combined model which shows backbone model combined with effects of scenarios.

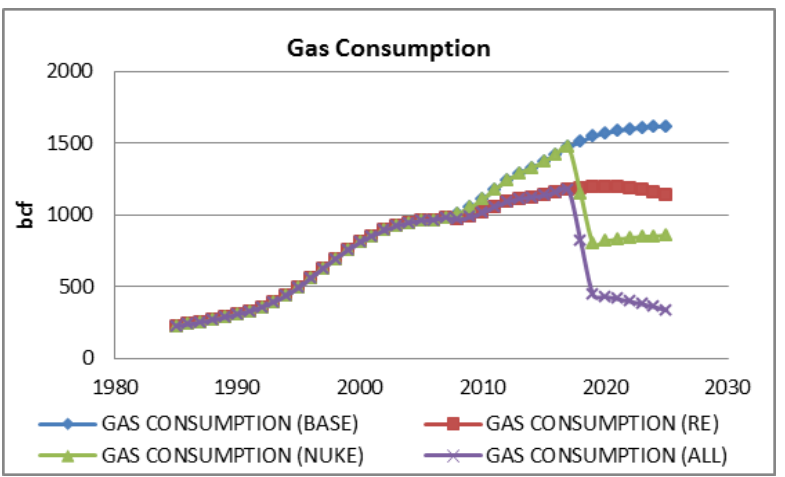

Fig. 11. Gas consumption from 1985 to 2025 for all scenarios.

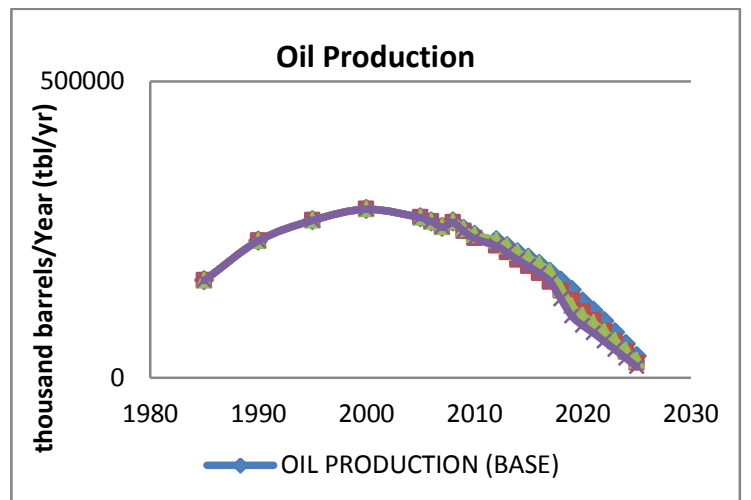

Fig. 12. Oil production from 1985 to 2025 for all scenarios.

For oil consumption, the BASE scenario shows a total of 259,074 thousand barrels per year for 2025, as shown in Fig. 13. With the implementation of RE scenario, the amount falls by $3 \%$. For NUKE and ALL scenarios, the amount decreases by $12 \%$ and $15 \%$ respectively.

Total $\mathrm{CO}_{2}$ emission for the BASE scenario is predicted at 177.79 million metric tons in the year 2025. In the RE scenario, the volume is predicted to fall by $16.7 \%$ whilst for scenarios NUKE and ALL, the volume of emission is predicted to reduce by $43 \%$ and $60 \%$ respectively as shown in Fig. 14. Total $\mathrm{CO}_{2}$ emission for Malaysia's oil and gas industry for 2005 to 2025 is shown in Table II.

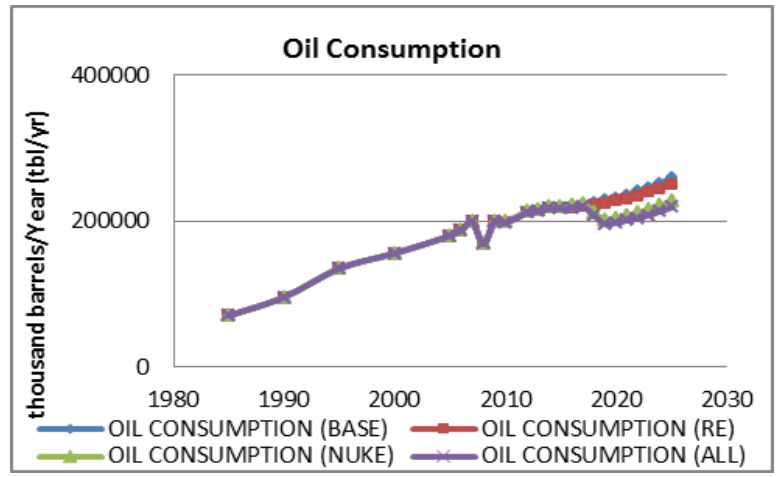

Fig. 13. Oil consumption from 1985 to 2025 for all scenarios.

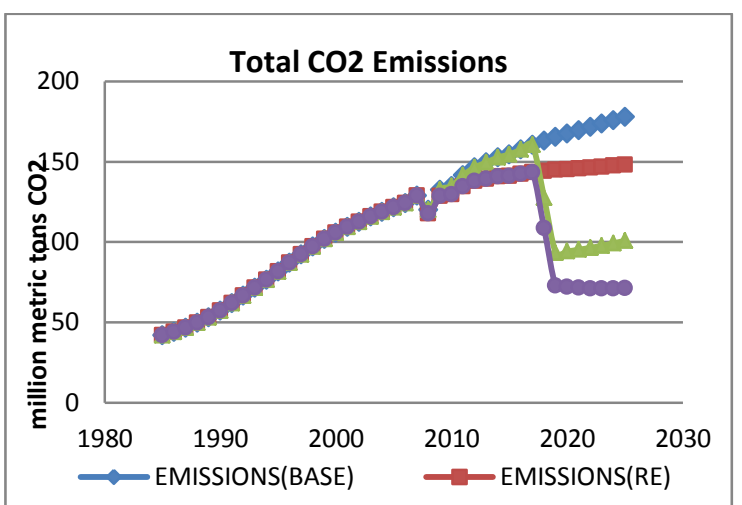

Fig. 14. Total $\mathrm{CO}_{2}$ emissions for oil and gas industry in Malaysia for all scenarios.

TABLE II: TOTAL $\mathrm{CO}_{2}$ EMISSION FOR MALAYSIA's OIL AND GAS INDUSTRY FROM 2005 TO 2025

\begin{tabular}{c|cccc}
\hline $\begin{array}{c}\text { Year/CO } \\
\text { Emissions } \\
\text { (Mtoe) }\end{array}$ & $\mathbf{2 0 0 5}$ & $\mathbf{2 0 1 5}$ & $\mathbf{2 0 2 0}$ & $\mathbf{2 0 2 5}$ \\
\hline BASE & 121.57 & 154.613 & 167.54 & 177.786 \\
RE & 121.57 & 141.068 & 145.239 & 148.05 \\
NUKE & 121.57 & 154.613 & 94.1949 & 100.896 \\
ALL & 121.57 & 141.068 & 71.8946 & 71.1596 \\
\hline
\end{tabular}




\section{B. Discussions}

Gas production and consumption is expected to decrease significantly with nuclear energy taking over as the main energy source in Malaysia, in line with government initiatives. Whilst currently the main energy source for power generation is natural gas, dominating the energy production sector by $60 \%$, this is expected to reduce to less than $20 \%$ with the implementation of the NUKE scenario where nuclear energy is dominant. Further, gas production and consumption is also expected to reduce significantly followed by the increased capacity for hydroelectric plants.

Although oil and gas production and consumption in Malaysia is predicted to decrease in all scenarios, the reduction it is not considered significant. This is due to the fact that the all scenarios only addressed the electricity generation sector; but the majority of oil production and consumption is primarily dominated by domestic, industrial and commercial transportation sector. It is not expected that this will be significantly affected by the implementation of NUKE scenario. The main factor influencing the amount of oil produced and consumed is expected to be the emergence of biofuel where it could potentially replace crude oil and its products in applications such as vehicle propulsion and power generation.

Generally, for all cases, nuclear energy scenario provides the highest percentage of reduction in $\mathrm{CO}_{2}$ emissions. Therefore, nuclear energy appears to be the most viable option for $\mathrm{CO}_{2}$ emissions, viewing in isolation only from the perspective of its emissions reduction potentials. However, this observation must be taken into consideration alongside Malaysia's limited experience with operating nuclear energy and its much contentious risk and safety management and assurance. It must also be considered that the economic viability of nuclear energy remains untested in Malaysia and parallel is not easily drawn from contemporary economies. With the maturity of nuclear energy production technology established, the key issue remains that nuclear energy and its implementation must be considered with its security and safety risks addressed. Otherwise, it is generally regarded that if Malaysia embarks upon its nuclear energy agenda, the advantages reap will far outweigh the precautions required.

Meanwhile, before nuclear energy can be fully implemented, a short term solution to $\mathrm{CO}_{2}$ emission reduction will be the use of renewable energies. Malaysia has a substantial hydro capacity when fully utilised; therefore this can be leveraged to push the agenda of emission reduction for the oil and gas production and consumption forward if properly implemented. Increased production of biofuel along with other green technologies will be needed in order to affect greater reduction. Malaysia's transportation sector is still heavily dependent upon fossil-based fuels e.g. petroleum and diesel. The demand for oil will continue to rise if other cleaner technologies are not viable. Policies to drive research, production and usage of electric, hybrid and other alternative-fuelled vehicles, are required to reduce emissions from transportation.

\section{CONCLUSION AND FURTHER WORK}

In conclusion, this project has investigated the dynamics of the oil and gas industry in Malaysia in order to predict the trend for power generation using oil and gas, resulting in an understanding of its $\mathrm{CO}_{2}$ emission trend when projecting into the future to consider its gradual displacement. This paper has also considered reducing the country's $\mathrm{CO}_{2}$ emissions from power generation with the implementation of different power generation options. It can be concluded that the pursuance of nuclear energy agenda in Malaysia could potentially lead to the greatest reduction of $\mathrm{CO}_{2}$ emissions if its economic viability is proven and its risks and safety issues can be addressed. Though the implementation of nuclear energy in Malaysia will be arduous, it is generally regarded that it will be the most efficient way to drive the reduction of $\mathrm{CO}_{2}$ emissions in the power generation sector.

From this study, it is proposed that further work should consider the economic impact of the gradual displacement of oil and gas with RE and nuclear energy as primary fuel for power generation in Malaysia. Work is also recommended on investigating the technical, economic and catastrophe risks of nuclear energy implementation in Malaysia.

\section{REFERENCES}

[1] C. S. Khor and G. Lalchand, "A review on sustainable power generation in Malaysia to 2030: Historical perspective, current assessment, and future strategies," Renewable and Sustainable Energy Reviews, vol. 29, pp. 952-960, Jan. 2014.

[2] K. A. Rahim and A. Liwan, "Oil and gas trends and implications in Malaysia," Energy Policy, vol. 50, pp. 262-271, 2012

[3] W. Ariffin, "The gas industry in Malaysia," Gasex 2008 Country Report, 2008.

[4] T. S. Jalal and P. Bodger, "National energy policies and the electricity sector in Malaysia," in Proc. the ICEE $20093^{\text {rd }}$ International Conference on Energy and Environment, 2009, pp. 440-448.

[5] M. H. Jayed, H. H. Masjuki, M. A. Kalam, T. M. I. Mahlia, M Husnawan, and A. M. Liaquat, "Prospects of dedicated biodiesel engine vehicles in Malaysia and Indonesia," Renewable and Sustainable Energy Reviews, vol. 15, pp. 220-235, 2011.

[6] H. Hashim and W. S. Ho, "Renewable energy policies and initiatives for a sustainable energy future in Malaysia," Renewable and Sustainable Energy Reviews, vol. 15, pp. 4780-4787, 2011.

[7] K. A. Bakar, M. F. M. Sam, M. N. H. Tahir, I. Rajiani, and N. Muslan, "Green technology readiness in Malaysia: Sustainability for business development," in Proc. the $2^{\text {nd }}$ International Conference on Business and Economy Research ( $2^{\text {nd }}$ ICBER 2011), Langkawi, Malaysia, 2011.

[8] T. H. Oh, S. Y. Pang, and S. C. Chua, "Energy policy and alternative energy in Malaysia: issues and challenges for sustainable growth," Renewable and Sustainable Energy Reviews, vol. 14, issue 4, pp. 1241-1252, May 2010

[9] World Energy Outlook. (2012). World energy outlook 2012 factsheet: How will global energy markets evolve to 2035. [Online]. Available: http://goo.gl/hA1f8Q

[10] EIA. (2014). Malaysia-Country analysis brief overview. [Online] Available: http://goo.gl/B51OzL

[11] Ministry of Natural Resources and Environment, Malaysia Second National Communication to the UNFCCC, 2008.

[12] REN21 Steering Committee. (2013). Renewables 2013: Global status report. [Online]. Available: http://goo.gl/PRrtNs

[13] Pemandu Malaysia. Chapter 6 - Oil, gas and energy. Economic transformation programme: A roadmap for Malaysia. [Online]. Available: http://goo.gl/ty7z8t

[14] Anylogic. (2014). Help — any logic advanced. [Online]. Available: http://goo.gl/R5Yh5Z

[15] System Dynamics. (2014). What is system dynamics? [Online]. Available: http://goo.gl/ZFdEXg

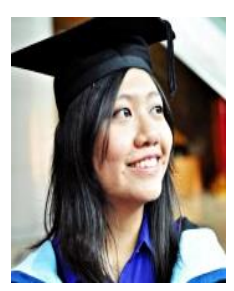

Hsieh Yie Lee graduated with a MEng (Hon) degree in mechanical engineering from the University of Nottingham, Malaysia Campus. She joined the university in 2010

She is currently a management trainee in St. Jude Medical Operations (M) Sdn Bhd in Penang, Malaysia. Whilst at the University of Nottingham Malaysia Campus, she worked under the supervision of Dr. Eng Hwa Yap in the area of sustainable system dynamics research, looking into the dynamics of oil and gas industry in Malaysia as her final year research. 


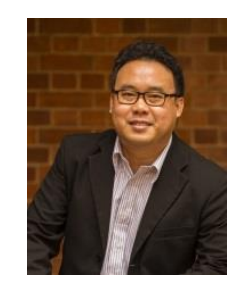

Eng Hwa Yap is a senior member of IACSIT. He obtained his $\mathrm{PhD}$ degree from University College London, United Kingdom in 2009 and BSc (Hon) degree in marine technology from the University of Plymouth, United Kingdom in 2002. He has also completed a postgraduate certificate in higher education at the University of Nottingham, Malaysia Campus in 2014.

$\mathrm{He}$ is currently a senior lecturer at UCL School of Energy and Resources, University College London in Adelaide, Australia He was formerly an associate professor at the Department of Mechanical, Materials and Manufacturing Engineering at the University of Nottingham,
Malaysia Campus where he served as the course director for MSc program in mechanical engineering and later the course director for UG Programs. His research work is focused on sustainable system dynamics modelling using energy technologies. He looks into the dynamics of such technologies' integration within the community with a focus on emerging economies.

Dr. Yap is a fellow of the Higher Education Academy, United Kingdom. He was awarded the CESA Smart Award for European Maritime Visions in 2007 jointly with Prof. Richard Bucknall, he had being the first awardee from a British university. Dr. Yap served in the technical committee for a number of international conferences and reviewed for a number of peer-reviewed journals including the Journal of Clean Energy Technologies and the Journal of Engineering, Science and Technology. 